Boise State University

ScholarWorks

Criminal Justice Faculty Publications and

Presentations

$10-2020$

\title{
An Examination of the Lethality Assessment Program (LAP): Perspectives on Implementation, Help-Seeking, and Victim Empowerment
}

\author{
Tara N. Richards \\ University of Nebraska \\ Lane Kirkland Gillespie \\ Boise State University \\ Katherine Kafonek \\ University of Delaware \\ Margaret Johnson \\ University of Baltimore
}

This article is protected by copyright and reuse is restricted to non-commercial and no derivative uses. Users may also download and save a local copy for the user's personal reference.

Richards, T.N.; Gillespie, L.K.; Kafonek, K. and Johnson, M. "An Examination of the Lethality Assessment Program (LAP): Perspectives on Implementation, Help-Seeking, and Victim Empowerment", Violence Against Women, 26(12-13), pp. 1517-1537. Copyright @ 2019, The Author(s). Reprinted by permission of SAGE Publications. https://doi.org/10.1177/1077801219880965 


\section{An Examination of the Lethality Assessment Program (LAP): Perspectives on Implementation, Help-Seeking, and Victim Empowerment}

\author{
Tara N. Richards, Ph.D.* \\ School of Criminology and Criminal Justice \\ University of Nebraska, Omaha \\ tararichards@unomaha.edu \\ Katherine Kafonek, M.S. \\ Department of Sociology and Criminal Justice \\ University of Delaware
}

\author{
Lane Kirkland Gillespie, Ph.D. \\ Department of Criminal Justice \\ Boise State University
}

Margaret Johnson, J.D.

School of Law

University of Baltimore

Article Information: Volume: 26 issue: 12-13, page(s): 1517-1537

Article First Published Online: October 29, 2019; Issue published: October 1, 2020

\section{Introduction}

Assessing the risk of violence in the context of criminal justice is not new (Hanson, 2005). Methods for predicting future criminal behavior have long been a policy goal among criminal justice scholars and practitioners. A more recent, related issue in this discussion is risk assessment in the context of victimization, specifically domestic violence victimization. Beginning in the 1980s several domestic violence risk assessments were developed and deployed in communities across the country (see Canales, Macaulay, McDougall, Wei, \& Campbell, 2013; Dutton \& Kropp, 2000; Hanson, Helmus, \& Bourgon, 2007; Messing \& Thaller, 2013; Nicholls, Pritchard, Reeves, \& Hilterman, 2013; Robinson \& Rowlands, 2009). Some of these risk assessments are intended to identify risk for any future abuse (no matter the severity) while others target lethality or severe re-victimization. Lethality assessments, in particular, are intended for use with victims as a means of promoting awareness of their risk for fatal abuse within their relationship and connecting them with services. One widely used example of such an assessment is the Lethality Assessment Program (LAP) - a two-step process including law enforcement screening and connection with a domestic violence advocate via telephone (see Lethality Assessment Program, n.d.).

While some scholars promote external assessments like the LAP as tools that assist service providers and victims alike in recognizing the seriousness of domestic violence (e.g., Campbell, 2005; Goodman, Dutton, \& Bennett, 2000), others have taken a more critical approach considering appropriateness, victims' own self-assessment, and the potential impact on victim empowerment and autonomy (Hoyle, 2008; Johnson, 2010; Klein, 2012; Websdale \& Dedolph, 2000). Further, the implementation of these tools has outpaced comprehensive empirical evaluation research. Nevertheless, there has been recent outcome evaluation research (e.g., Messing, Campbell, Webster, Brown, Patchell, \& Wilson, 2015) and critical theoretical discussion regarding the implementation of lethality assessments and their potential influence on domestic violence service utilization and victim empowerment (e.g., Birdsall, Kirby, \& McManus, 2017; Johnson, 2010). What follows is a description of the development of the Lethality Assessment Program (LAP); discussion of evaluations and critiques of the LAP; and a description of the current study, which aims to address the need for additional external evaluation and assessment of the LAP implementation from a victim empowerment perspective.

\section{The Lethality Assessment Program (LAP)}

The LAP is a two-part collaborative effort between law enforcement officers and social service providers in the community aimed at increasing victims' awareness about their risk for re-assault and homicide by an abuser, improving the utilization of emergency safety planning services for victims of domestic violence, and ultimately decreasing domestic violence-related victimization and homicides (MNADV, n.d.). The LAP protocol includes the administration of the Lethality Screen to the victim by the responding officer, and the "Protocol Referral" - the immediate connection between victims who fit the Lethality Screen's high-risk criteria and a local domestic violence hotline counselor or advocate (Messing, Campbell, Brown, Patchel, Androff, \& Wilson, 2014). The Lethality Screen 
This is an author-produced, peer-reviewed version of this article. The final, definitive version of this document can be found online at Violence Against Women, published by SAGE. Copyright restrictions may apply. https://doi.org/10.1177/1077801219880965. The content of this document may vary from the final published version.

is an 11-item adaption of the 20-item actuarial tool utilized as part of the Danger Assessment, one of the common (and in its full form, particularly unique) forms of structured professional judgement (see Campbell, 1986; Campbell, 1995; Storey \& Hart, 2014).

According to the Maryland Network Against Domestic Violence (MNADV) (n.d.), the LAP aims to assist both the victim and the law enforcement officer to recognize that the individual may be at increased risk for severe future violence. Law enforcement officers responding to a domestic violence call use the Lethality Screen if the officer believes an assault or violent act has occurred, if the officer is concerned for the safety of the victim once they leave the scene, if domestic violence has occurred at the location in the past, or if the officer has a "gut feeling" that the victim is in danger (Messing et al., 2014; MNADV, n.d.). If the victim's responses to the screen indicate highdanger $^{1}$, or if the law enforcement officer judges that the victim is at high risk, then the law enforcement officer should explain to the victim that a "high-danger" screen means that their risk for homicide is high, and ask the victim to speak with an advocate via the collaborating victim service agency emergency hotline.

If the victim declines to speak to the advocate, the LAP protocol indicates that law enforcement officers should engage in multiple attempts to connect the victim to the emergency hotline. If the victim declines to speak to the hotline operator after multiple attempts, then the law enforcement officer should relay safety-planning advice to the victim directly (https://lethalityassessmentprogram.org). For victims who are not assessed as "high danger" the law enforcement officer does not contact a victim advocate, but instead should explain that, "IPV can be dangerous, provide her with information about risk factors for homicide, and refer her to local domestic violence services" (Messing et al., 2015, p. 508). Thus, the LAP hinges on law enforcement training and judgement, and cooperation between law enforcement agencies and domestic violence advocates (Messing, Campbell, Wilson, Brown, Patchell, \& Shall, 2014).

Despite the implementation of the LAP in multiple states (e.g., Maryland, Connecticut, North Carolina, Pennsylvania, Florida, and others), empirical literature evaluating the program is limited. The MNADV does provide annual data tracking the utilization of services among victims who come into contact with the LAP in Maryland. In 2015, law enforcement officers were involved in 11,839 lethality screens: $52 \%$ of victims were assessed as "high danger", $33 \%$ were assessed as "non-high danger", and 15\% did not answer the lethality screen (MNADV, 2016). Of those victims who were assessed as high danger, 45\% spoke to a counselor and 58\% of those who spoke to a counselor sought services. Furthermore, approximately $26 \%$ of victims who were assessed as high danger by law enforcement officers sought services. Although this data presents a picture of service utilization by victims receiving the LAP at the time of a domestic violence incident, it does not provide information on victims of domestic violence who do not receive the LAP or provide information about the LAP process or victim's decisionmaking beyond the crisis intervention point (i.e., law enforcement contact).

Recent studies have aimed to examine and evaluate aspects of the LAP's implementation (Messing, Campbell, Ward-Lasher, Brown, Patchell, \& Wilson, 2016; Messing, Cimino, Campbell, Brown, Patchell, \& Wilson, 2011) and the screen's predictive validity (Messing \& Campbell, 2016; Messing, Campbell, Wilson, Brown, \& Patchell, 2017). To our knowledge, only one study to date has evaluated the potential impact of the LAP using a comparison group. Using a quasi-experimental, non-equivalent group design, Messing and colleagues $(2014,2015)$ compared two groups of female IPV victims, a treatment group who received the LAP from law enforcement officers (and spoke to a hotline advocate) $(\mathrm{n}=347)$ and a comparison group who received a card with "advocacy information" from law enforcement officers ( $\mathrm{n}=433)$, in regard to differences in 16 self-protective behaviors. Six-month followup interviews were also completed with 202 participants from the treatment group and 212 participants from the comparison group.

Regression analyses demonstrated that victims who received the LAP were significantly more likely than those in the comparison group to endorse two of the 16 self-protective measures, having removed or hidden her partner's weapons and/or received domestic violence services, during the six months prior to the law enforcement service call for domestic violence or the time in between the call for service and the baseline interview with the researchers. Further, regression results from the six-month follow-up interview indicated that victims in the LAP group were significantly more likely than those in the comparison group to report engaging in eight other self-protective actions:

\footnotetext{
${ }^{1}$ i.e., the victim endorses one of the following: the perpetrator has access to weapons, there has been prior strangulation, recent separation, extreme jealousy and/or controlling behaviors, perpetrator suicide attempts, stalking, or unemployment, or if the victim has a child that is not the perpetrator's (MNADV, 2011).
} 
This is an author-produced, peer-reviewed version of this article. The final, definitive version of this document can be found online at Violence Against Women, published by SAGE. Copyright restrictions may apply. https://doi.org/10.1177/1077801219880965. The content of this document may vary from the final published version.

establishing a code with family/friends, obtaining something to protect herself, engaging in other protective action, applying for a protective order, receiving a protective order, obtaining medical care due to violence, going somewhere her partner could not find her (hid), and her partner went somewhere he could not see her (detained) (Messing et al., 2015).

Taken together, Messing et al. (2015) concluded that the LAP was effective in increasing self-protective actions by victims of IPV when compared to victims of IPV that received routine police service. At the same time, the authors called for future research - especially qualitative and observational research - focused on the implementation of the LAP, women's experiences with the LAP, and their perceptions of the LAP process. Messing and colleagues (2015) specifically noted that, "the LAP is intended to encourage survivors to take action for self-care and should in no way be coercive or compromise women's autonomy" (p. 521). This concern regarding victim empowerment and autonomy has been raised elsewhere (see Johnson, 2010) and, in addition to evaluating service utilization, is a focus of the current study.

\section{Empowerment \& the LAP}

While the creators of the LAP purport that the protocol was developed with victim empowerment in mind, others (Johnson, 2010; Storey \& Hart, 2014; Websdale \& Dedolph, 2000) have suggested that lethality assessment may require refinement in order to ensure victims understand the limitations of assessment and are treated with dignity during the process. The goal of empowerment is common in the context of domestic violence, and is emphasized in the risk assessment literature as a goal of assessment as well. In the context of domestic violence, discussing risk with a victim is meant provide an avenue for obtaining knowledge and feedback to assist victims in making fully informed decisions about their life, particularly as it pertains to their relationship. As described by Cattaneo and Goodman (2010) there are "two components at the core of empowerment: a psychological sense of power-an understanding of what one wants and needs and a feeling one can reach those goals - and a real ability to affect change in important outcomes" (p. 483-84). Thus, interventions that facilitate empowerment for victims of domestic violence will provide avenues for victims to gain (or regain) power from their batterer and/or the state (i.e., criminal justice system) regarding decisionmaking processes. Aligning with empowerment goals, the LAP aims to provide victims with an awareness of their lethality risk that they can then weigh with their own assessment in making decisions about their future and safety. The LAP intends for victims to have the option to accept or refuse being screened, and to accept or refuse to speak with an advocate if they do screen-in as high risk for lethality. Providing the option is meant to be a mechanism for allowing victims to assert power over decision-making that affects their lives, and acknowledgement that self-assessment should be respected. However, it is concern about the value of empowerment and dignity that has led to critique of the LAP, particularly in light of limited evaluation.

Specifically, Johnson's (2010) legal analysis of the LAP and its implementation within the justice system outlined concerns regarding the use of a state intervention that emphasizes a goal of saving lives as paramount to a goal of victim dignity and empowerment. First, Johnson contended that the LAP fundamentally assumes that abused women, especially those at the highest risk for lethality, are not already taking actions to protect themselves. Second, citing evidence of the accuracy of women's own predictions regarding re-assault risk, she also emphasized that risk assessment instruments have, in part, been developed by researching victim self-assessments and the factors women themselves consider in risk evaluation. Furthermore, Johnson argued that while research findings do indicate that neither women nor risk assessment tools are completely accurate, the implementation of the LAP may create a narrative of women suffering from a "false consciousness" (2010, p. 561) that can be remedied by assessment. Thus, from an empowerment perspective the concern is that implementation of the LAP emphasizes one goal: service connection to reduce homicide risk; as opposed to viewing women as "active decisionmakers [...] [whose] decisionmaking involves weighing options against consequences in their full lives, as opposed to simply accepting that accessing services will reduce homicide risk" (Johnson, 2010, p. 563).

Further, the nature of the LAP as a point-in-time assessment must be considered - especially as it relates to victim empowerment. The LAP is limited in that is considers only the abuser's behavior up until the point of the LAP screen, however, it is well understood that domestic violence is complex and may (or may not) escalate over time (see Piquero, Brame, Fagan, \& Moffitt, 2006). As such, any assessment of victim risk must be predicated on the potential that a victim's risk may change (Hoyle, 2008). Victims must not supplant their own judgment regarding risk and safety simply because a law enforcement officer indicates that they do or do not fall into a certain risk "category" at a given time (Kropp, 2004; Websdale \& Dedolph, 2000). Such contentions underscore the importance of evaluating service utilization in concert with victims' experiences and perceptions of the LAP. 
This is an author-produced, peer-reviewed version of this article. The final, definitive version of this document can be found online at Violence Against Women, published by SAGE. Copyright restrictions may apply. https://doi.org/10.1177/1077801219880965. The content of this document may vary from the final published version.

It is important to note that no empirical research to date has evaluated the LAP process in order to assess how victims are interpreting their options in the LAP. Information has been collected from law enforcement officers indicating their support of the program, at least as it pertains to raising their awareness, but as Johnson points out "unlike system actors [...] women subjected to abuse have not yet been systematically surveyed for their opinions on the effectiveness of the LAP" (2010, p. 565). In service to this critical gap in knowledge, this study examines victims' service utilization, self-protective behavior, and perceptions of the LAP process and does so from a victim empowerment perspective.

\section{Current Study}

According to the MNADV, the purpose of the LAP is to "save women's lives" by (1) "helping women self identify" and (2) "encouraging them to seek domestic violence services" (MNADV, 2009). While the potential utility of a screening tool for first responders is clear, concerns have been expressed regarding the degree to which these assessments implemented at one time point may miss the dynamic nature of domestic violence risk, and furthermore, may impact the underlying goal of victim empowerment. Depending on the implementation of the LAP, victims may be empowered to access services or lose agency and/or feel coerced into participating in the screening process. In this vein, the current research aims to assess whether receiving the LAP impacts women's utilization of self-protective measures and services. In addition, for women who have received the LAP, their LAP experience and satisfaction with services post-LAP are examined. Consistent with the goals of the LAP, the following hypotheses guided the present study:

(1) Women who report receiving the LAP will report increased use of self-protective actions compared with women who do not report receiving LAP.

(2) Women who report receiving the LAP will report increased use of formal domestic violence services compared with women who do not report receiving LAP.

(3) Women who report receiving the LAP will report increased victim empowerment compared with women who do not report receiving LAP.

(4) Women who report receiving the LAP will have a clear understanding of the reason why the LAP was performed and their results from the LAP screen, consistent with the LAP's mission to raise awareness and save women's lives.

\section{Methodology}

\section{Data Collection and Sample}

The recruitment of domestic violence victims for research purposes is challenging. Previous evaluations of the LAP have used law enforcement responding to domestic violence calls to recruit participants. This method makes sense given the natural opportunity to intervene, but using law enforcement to recruit participants into a scientific study in the midst of a potentially traumatic experience may be both uncomfortable for the officer and overwhelming for the victim (Messing et al., 2011). The current study utilized an alternative recruitment approach by eliciting participation from women who were seeking domestic violence services, an approach which has its own benefits and challenges. Regarding benefits, (1) participants are further removed from the domestic violence incident and are thus less likely to be "in crisis", (2) individuals who do not report LAP receipt are easily accessible and can be enrolled in the study to provide valuable information as a comparison group, and (3) participants who report having received the LAP are able to reflect on their experience with the process. Regarding challenges, (1) both groups consist of women currently seeking domestic violence-related services, thus the women in the sample may already be more empowered to seek services than women drawn from law enforcement samples, and (2) given that some amount of time has passed since LAP receipt, and that women may have been in crisis during receipt, the accuracy of their recollection may be reduced. Despite these challenges the current study's approach provides an initial comparison of help-seeking between women who have and have not received the LAP, as well as insight into the LAP process from the victim's perspective.

Specifically, we solicited participation from a cohort of clients seeking services at a not-for-profit organization providing pro-bono legal services in domestic violence cases (hereafter legal aid center) in multiple jurisdictions in a Mid-Atlantic state from May 1, 2015 to May 30, 2016. Trained victim advocates working at the legal aid centers collected data for the current study in the course of their regular intake. Prior to the start of any data collection, the 
This is an author-produced, peer-reviewed version of this article. The final, definitive version of this document can be found online at Violence Against Women, published by SAGE. Copyright restrictions may apply. https://doi.org/10.1177/1077801219880965. The content of this document may vary from the final published version.

three victim advocates (as well as the legal aid center attorneys, legal aid center director, and associate director) completed a one-day training regarding the purpose of the study and the survey instrument. After the initial training, a graduate research assistant was available to answer any questions from staff members on an as needed basis.

During the study period, the trained legal aid center staff informed new clients about the research study and inquired as to whether they would be willing to participate. Participants were informed that the study was voluntary and that their participation (or their decision not to participate) would not impact their ability to obtain services or the quality of their services at the legal aid center. Clients who expressed interest in participating completed the informed consent process with a legal aid center staff person and the research protocol was added to their intake process. Participants were not compensated for their participation.

A trained graduate research assistant visited the legal aid center sites every month and (1) retrieved the signed informed consent forms and (2) entered the survey data into a SPSS 23 dataset. To protect participant's privacy and confidentiality, participants were assigned a subject number, which was utilized in all data files associated with the study. This research was approved by the Institutional Review Board at the lead author's University.

Of the 220 clients served by the legal aid center between May 1, 2015 and May 30, 2016, 64\% agreed to participate. Demographic data was compared for participants $(n=141)$ and non-participants $(n=79)$ and significant differences were detected between participants and non-participants regarding race, education, and living status. Specifically, participants were significantly more likely to be White, had higher educational attainment (beyond a high school diploma), and were less likely to be living with their partner.

\section{Treatment and Comparison Groups}

The current research compares women seeking domestic violence services who reported that they previously received the Lethality Assessment Program (LAP) and those who reported that they had never received the LAP in regard to self-protective measures and service utilization. In addition, among participants who reported that they received the LAP, participant's satisfaction with the LAP process was examined. In order to determine group assignment, consented participants were shown questions from the LAP and asked if they had ever received the LAP in response to an experience with domestic violence by their current partner. Slightly less than half of participants $(\mathrm{n}=66 ; 47 \%)$ reported that they had previously received the Lethality Assessment Program (LAP) and are considered our treatment group; the 53\% of participants who reported that they had not received the LAP ( $=75)$ are utilized as the comparison group. No significant bivariate differences were uncovered between the treatment and comparison groups regarding the demographic variables or the severity of IPV variables (see Table 1 below).

The study sample includes 141 women seeking assistance with a domestic violence protection order from a legal aid center in a Mid-Atlantic state between May 1, 2015 and May 30, 2016. Participants ranged in age from 18 to 74 years old; their average age was 34 years old ( $\mathrm{SD}=10.5$ years). Participants identified as White (54\%), African American (35\%), Latina (7\%), Native American $(<1 \%)$, or Multi-racial $(6 \%)$. The majority of participants reported more than a high school diploma (65\%) and that they were currently single and not living with a partner (87\%). Participants reported caring for between 0 and 7 dependent children, and on average 1 child (SD=1.17). Regarding severity of IPV, participants reported scores of 0-20 for psychological IPV with an average score of 12.36 ( $\mathrm{SD}=5.67), 0-35$ for physical IPV with an average score of 9.55 ( $\mathrm{SD}=9.33$ ), and 0-16 for sexual coercion with an average score of $2.90(\mathrm{SD}=4.12)$. As presented in Table 1, there were no significant differences between participants who had previously received the LAP and those who had not received the LAP on any of the demographic variables or the severity of psychological, physical, or sexual domestic violence. 
This is an author-produced, peer-reviewed version of this article. The final, definitive version of this document can be found online at Violence Against Women, published by SAGE. Copyright restrictions may apply. https://doi.org/10.1177/1077801219880965. The content of this document may vary from the final published version.

Table 1. Demographics and Severity of Domestic Violence Information for Respondents in the LAP Group versus No LAP Group

\begin{tabular}{|c|c|c|c|c|c|c|c|}
\hline & \multicolumn{2}{|c|}{$\begin{array}{c}\text { Total Sample } \\
\quad \mathrm{N}=141\end{array}$} & \multicolumn{2}{|c|}{$\begin{array}{c}\text { LAP } \\
n=66(47 \%)\end{array}$} & \multicolumn{2}{|c|}{$\begin{array}{c}\text { No LAP } \\
n=75(53 \%)\end{array}$} & \multirow[t]{2}{*}{$t / x^{2}$} \\
\hline & $\mathrm{N}$ & $\%$ & $\mathrm{~N}$ & $\%$ & $\mathrm{~N}$ & $\%$ & \\
\hline Mean Age & 34.17 & - & 34.67 & - & 33.75 & - & $t=0.52$ \\
\hline SD & 10.5 & - & 9.07 & - & 11.67 & - & \\
\hline Range & $18-74$ & - & $20-53$ & - & $18-74$ & - & \\
\hline Race/Ethnicity & & & & & & & $x^{2}=5.55$ \\
\hline White & 76 & $54 \%$ & 42 & $64 \%$ & 34 & $45 \%$ & \\
\hline African American & 49 & $35 \%$ & 19 & $29 \%$ & 30 & $40 \%$ & \\
\hline Latina & 7 & $5 \%$ & 2 & $3 \%$ & 5 & $7 \%$ & \\
\hline Native American & 1 & $>1 \%$ & 0 & $0 \%$ & 1 & $1 \%$ & \\
\hline Other/Multi-Racial & 8 & $6 \%$ & 3 & $5 \%$ & 5 & $7 \%$ & \\
\hline Educational Status & & & & & & & $x^{2}=3.57$ \\
\hline $\begin{array}{l}\text { No high school } \\
\text { degree/GED }\end{array}$ & 11 & $8 \%$ & 3 & $4 \%$ & 8 & $11 \%$ & \\
\hline $\begin{array}{l}\text { High school } \\
\text { degree/GED }\end{array}$ & 38 & $27 \%$ & 15 & $23 \%$ & 23 & $31 \%$ & \\
\hline $\begin{array}{l}\text { More than high } \\
\text { school/GED }\end{array}$ & 92 & $65 \%$ & 48 & $73 \%$ & 44 & $59 \%$ & \\
\hline Relationship Status & & & & & & & $x^{2}=0.54$ \\
\hline Single & 73 & $52 \%$ & 32 & $48 \%$ & 41 & $55 \%$ & \\
\hline Married & 30 & $21 \%$ & 15 & $23 \%$ & 15 & $20 \%$ & \\
\hline Divorced/Separated & 38 & $27 \%$ & 19 & $29 \%$ & 19 & $25 \%$ & \\
\hline Living Status & & & & & & & $x^{2}=0.05$ \\
\hline $\begin{array}{l}\text { Currently living with } \\
\text { partner }\end{array}$ & 18 & $13 \%$ & 8 & $12 \%$ & 10 & $13 \%$ & \\
\hline $\begin{array}{l}\text { Not currently living } \\
\text { with partner }\end{array}$ & 123 & $87 \%$ & 58 & $88 \%$ & 65 & $87 \%$ & \\
\hline $\begin{array}{l}\text { Mean Number of } \\
\text { Dependents }\end{array}$ & 1.35 & - & 1.30 & - & 1.40 & - & $t=0.49$ \\
\hline SD & 1.17 & - & 1.02 & - & 1.28 & - & \\
\hline Range & $0-7$ & - & $0-4$ & - & $0-7$ & - & \\
\hline Mean Psychological DV & 12.36 & - & 12.41 & - & 12.32 & - & $t=-0.09$ \\
\hline $\mathrm{SD}$ & 5.67 & - & 6.09 & - & 5.30 & - & \\
\hline Range & $0-20$ & - & $0-20$ & - & $0-20$ & - & \\
\hline Mean Physical DV & 9.55 & - & 10.26 & - & 8.92 & - & $t=-0.85$ \\
\hline $\mathrm{SD}$ & 9.33 & - & 10.16 & - & 8.58 & - & \\
\hline Range & $0-35$ & - & $0-35$ & - & $0-29$ & - & \\
\hline Mean Sexual DV & 2.9 & - & 3.92 & - & 2.53 & - & $t=-1.15$ \\
\hline $\mathrm{SD}$ & 4.12 & - & 4.34 & - & 3.33 & - & \\
\hline Range & $0-16$ & - & $0-16$ & - & $0-16$ & - & \\
\hline
\end{tabular}


This is an author-produced, peer-reviewed version of this article. The final, definitive version of this document can be found online at Violence Against Women, published by SAGE. Copyright restrictions may apply. https://doi.org/10.1177/1077801219880965. The content of this document may vary from the final published version.

\section{$\underline{\text { Measures }}$}

Participant's past year experience with physical and psychological domestic violence victimization and sexual coercion by their intimate partner was measured using items from the Revised Conflict Tactics Scale (CTS2; Straus, Hamby, Boney-McCoy, \& Sugarman, 1996). To measure Physical IPV, participants were asked if they had experienced the following nine behaviors in their current relationship with their abusive partner. In the past year, has your partner ever: (a) thrown something at you that could hurt, (b) twisted your arm or hair, (c) kicked you, (d) slapped you, (e) pushed or shoved you, (f) punched or hit you with their hand or an object, (g) choked you, (h) slammed you against the wall, and (i) grabbed you. Psychological IPV was captured by asking if they had experienced the following five behaviors in their current relationship with their abusive partner. In the past year, has your partner ever: (a) shouted or yelled at you, (b) called you bad names, (c) accused you of being a lousy lover, (d) insulted or swore at you, (e) threatened to hit or throw something at you. Sexual coercion was measured using the following four questions. In the past year, has your partner ever: (a) used threats to make you have sex, (b) made you have sex without a condom, (c) used force (like hitting, holding down, or using a weapon) to make you have sex (vaginal, oral, and/or anal), and (d) insisted on sex (vaginal, oral, and/or anal) when you did not want to (but did not use physical force). Responses included $0=$ not in the past year, $1=$ one time in the past year, $2=$ two times in the past year, $3=$ three to five times in the past year, and $4=$ six or more times in the past year. Respondents' scores on each of the three measures were computed to create total scores. Alpha scores for each of the measures were above the acceptable cutoff value: Physical IPV $\alpha=.91$, Psychological IPV $\alpha=.74$, and Sexual Coercion $\alpha=.76$.

Self-protective actions were measured using the Safety Promoting Behavior Checklist (McFarlane, Malecha, Gist, Watson, Batten, Hall, \& Smith, 2004; see also Messing et al., 2014). Participants were asked whether they had taken any of the 15 actions on the checklist during their relationship with their abusive partner (yes $=1$, no= 0 ).

Participants were also asked about their service utilization including safety planning, counseling, shelter services, and protective orders, and satisfaction with such services. Participants who had received the LAP were also asked whether they sought such services after receiving the LAP.

Empowerment was measured using 14 questions based on the Personal Progress Scale Revised (Johnson, Worrell, \& Chandler, 1998; 2005). Responses included $1=$ never true, $2=$ sometimes true, $3=$ mostly true, $4=$ always true $(\alpha$ $=.76)$.

\section{Results}

First, we completed bivariate comparisons for participants who had previously received the LAP and those who had not received the LAP in regard to their self-reported scores on the Safety Promoting Behavior Checklist (McFarlane et al., 2004). Contrary to our hypothesis, participants who had received the LAP did not report significantly higher rates of self-protective actions compared to participants who had not received the LAP. 
This is an author-produced, peer-reviewed version of this article. The final, definitive version of this document can be found online at Violence Against Women, published by SAGE. Copyright restrictions may apply. https://doi.org/10.1177/1077801219880965. The content of this document may vary from the final published version.

Table 2. Comparisons of Self Protective Measures Taken by Respondents in the LAP Group versus No LAP Group

\begin{tabular}{|c|c|c|c|c|c|}
\hline & \multicolumn{2}{|c|}{$\begin{array}{c}\text { LAP } \\
\mathrm{n}=66(47 \%)\end{array}$} & \multicolumn{2}{|c|}{$\begin{array}{c}\text { No LAP } \\
\mathrm{n}=75(53 \%)\end{array}$} & \multirow[t]{2}{*}{$x^{2}$} \\
\hline & YES & NO & YES & NO & \\
\hline $\begin{array}{l}\text { Has client ever hidden money, an extra set of } \\
\text { house keys, car keys, or another belonging or } \\
\text { object that may help her flee relationship }\end{array}$ & 36 & 30 & 31 & 44 & 2.46 \\
\hline $\begin{array}{l}\text { Has client ever established a code with family } \\
\text { or friends (to let them know when she is in } \\
\text { trouble) }\end{array}$ & 18 & 48 & 24 & 51 & 0.38 \\
\hline $\begin{array}{l}\text { Has client asked neighbors to call the police if } \\
\text { violence begins }\end{array}$ & 20 & 46 & 15 & 60 & 2.00 \\
\hline $\begin{array}{l}\text { Has client removed or hidden partner's } \\
\text { weapons }\end{array}$ & 11 & 55 & 9 & 66 & 0.63 \\
\hline $\begin{array}{l}\text { Has client made available paperwork such as } \\
\text { social security numbers, rent and utility } \\
\text { receipts, birth certificates, bank account } \\
\text { numbers, driver's license or ID, or insurance } \\
\text { policies or numbers }\end{array}$ & 27 & 39 & 51 & 24 & 1.21 \\
\hline Has client hidden valuable jewelry & 16 & 50 & 12 & 63 & 1.50 \\
\hline Has client hidden extra money & 32 & 34 & 35 & 40 & 0.05 \\
\hline $\begin{array}{l}\text { Has client made available a hidden bag with } \\
\text { extra clothing }\end{array}$ & 19 & 47 & 19 & 56 & 0.21 \\
\hline $\begin{array}{l}\text { Has client gone some place where partner } \\
\text { couldn't find or see her }\end{array}$ & 42 & 24 & 41 & 34 & 1.17 \\
\hline $\begin{array}{l}\text { Has there been a period in the past } 6 \text { months } \\
\text { when client didn't see partner for a while } \\
\text { because one or both chose not to }\end{array}$ & 32 & 34 & 39 & 36 & 0.17 \\
\hline $\begin{array}{l}\text { Has client ever been treated by a doctor or } \\
\text { nurse for injuries or trauma that partner caused } \\
\text { in this relationship }\end{array}$ & 26 & 40 & 28 & 47 & 0.06 \\
\hline $\begin{array}{l}\text { Has client ever received services related to } \\
\text { domestic violence in this relationship }\end{array}$ & 5 & 61 & 6 & 69 & 0.01 \\
\hline
\end{tabular}


This is an author-produced, peer-reviewed version of this article. The final, definitive version of this document can be found online at Violence Against Women, published by SAGE. Copyright restrictions may apply. https://doi.org/10.1177/1077801219880965. The content of this document may vary from the final published version.

Next, we compared service utilization between the LAP group and the No LAP group. Consistent with our hypothesis, results indicated that participants in the LAP group reported greater rates of safety planning service utilization $\left(x^{2}=5.51, \mathrm{p}<.05\right)$ and applications for previous protection/restraining orders $\left(x^{2}=4.42, \mathrm{p}<.05\right)$ compared to the No LAP group. However, follow-up questioning uncovered that only a slight majority of participants in the LAP group who received safety-planning services (59\%) did so after receiving the LAP. In addition, few participants in the LAP group who had previously sought out applications for protection/restraining orders (18\%) did so after receiving the LAP. No differences were observed between the LAP and No LAP group in regard to seeking shelter services or counseling services.

Table 3. Comparisons of Service Utilization by Participants in the LAP Group versus No LAP Group

\begin{tabular}{|c|c|c|c|c|c|}
\hline & \multicolumn{2}{|c|}{$\begin{array}{c}\text { LAP } \\
n=66(47 \%)\end{array}$} & \multicolumn{2}{|c|}{$\begin{array}{c}\text { No LAP } \\
n=75(53 \%)\end{array}$} & \multirow[t]{2}{*}{$x^{2}$} \\
\hline & YES & NO & YES & $\mathrm{NO}$ & \\
\hline Has client received shelter services? & 5 & 61 & 6 & 69 & 0.01 \\
\hline $\begin{array}{l}\text { Did client seek shelter services after the } \\
\text { Lethality Screen? }\end{array}$ & 4 & 1 & - & - & \\
\hline Has client received counseling services? & 17 & 47 & 20 & 55 & 2.31 \\
\hline $\begin{array}{l}\text { Did client seek counseling services after } \\
\text { the Lethality Screen? }\end{array}$ & 8 & 9 & - & - & \\
\hline $\begin{array}{l}\text { Has client received safety-planning } \\
\text { services? }\end{array}$ & 18 & 47 & 9 & 66 & $5.51 *$ \\
\hline $\begin{array}{l}\text { Did client seek safety-planning services } \\
\text { after the Lethality Screen? }^{\text {a }}\end{array}$ & 10 & 7 & - & - & \\
\hline $\begin{array}{l}\text { Has client received assistance with another } \\
\text { application for a protection/restraining order } \\
\text { against her partner? }\end{array}$ & 17 & 49 & 9 & 66 & $4.42 *$ \\
\hline $\begin{array}{l}\text { Did client seek the previous application } \\
\text { for a protection/restraining order after the } \\
\text { Lethality Screen? }\end{array}$ & 3 & 14 & - & - & \\
\hline
\end{tabular}

$* p<.05$

Note: ${ }^{\mathrm{a}}$ one participant elected not to answer the question 
This is an author-produced, peer-reviewed version of this article. The final, definitive version of this document can be found online at Violence Against Women, published by SAGE. Copyright restrictions may apply. https://doi.org/10.1177/1077801219880965. The content of this document may vary from the final published version.

Next, mean scores for the series of empowerment items were compared for individuals in the LAP group and the No LAP group. Findings are presented in Table 4. Results demonstrated that there were no significant differences between in the LAP group and the No LAP group regarding mean scores for any of the empowerment items.

Table 4. Comparisons of Empowerment by Participants in the LAP Group versus No LAP Group

\begin{tabular}{|c|c|c|c|}
\hline & $\begin{array}{l}\text { LAP } \\
n=66(47 \%)\end{array}$ & $\begin{array}{c}\text { No LAP } \\
\mathrm{n}=75(53 \%)\end{array}$ & $t$ \\
\hline $\begin{array}{l}\text { I can cope with whatever challenges come at me as I } \\
\text { work to reach my goals of life satisfaction. }\end{array}$ & 3.00 & 3.10 & 1.43 \\
\hline $\begin{array}{l}\text { I have to give up too much to reach my goals of life } \\
\text { satisfaction. }\end{array}$ & 1.70 & 1.80 & 0.48 \\
\hline $\begin{array}{l}\text { I know what to do in response to threats to my being } \\
\text { able to reach my goals of life satisfaction. }\end{array}$ & 3.00 & 3.00 & 0.03 \\
\hline $\begin{array}{l}\text { I have a good idea about what kinds of support I can } \\
\text { get from people in my community (friends, family, } \\
\text { neighbors, people in my faith community, etc.) to } \\
\text { reach my goals of life satisfaction. }\end{array}$ & 3.00 & 2.90 & -0.44 \\
\hline $\begin{array}{l}\text { I know what my next steps are on the path to } \\
\text { reaching my goals of life satisfaction. }\end{array}$ & 3.00 & 3.10 & 0.80 \\
\hline $\begin{array}{l}\text { Working to reach my goals of life satisfaction creates } \\
\text { (or will create) new problems for me. }\end{array}$ & 2.00 & 1.80 & -1.19 \\
\hline $\begin{array}{l}\text { When something doesn't work to reach my goals of } \\
\text { life satisfaction, I can try something else. }\end{array}$ & 3.40 & 3.30 & -0.90 \\
\hline $\begin{array}{l}\text { I feel comfortable asking for help to reach my goals } \\
\text { of life satisfaction. }\end{array}$ & 3.10 & 3.10 & -0.04 \\
\hline $\begin{array}{l}\text { When I think about being satisfied with my life, I } \\
\text { have a clear sense of my goals for the next few years. }\end{array}$ & 3.00 & 3.00 & -0.08 \\
\hline $\begin{array}{l}\text { Being the decision-maker about how best to address } \\
\text { the abuse in my life will help me reach my goals of } \\
\text { life satisfaction. }\end{array}$ & 3.40 & 3.20 & -1.18 \\
\hline $\begin{array}{l}\text { Working to reach my goals of life satisfaction creates } \\
\text { (or will create) new problems for people I care about. }\end{array}$ & 1.90 & 1.90 & -0.18 \\
\hline $\begin{array}{l}\text { I feel confident in the decisions I make to reach my } \\
\text { goals of life satisfaction. }\end{array}$ & 3.10 & 3.20 & 0.62 \\
\hline $\begin{array}{l}\text { I have a good idea about what kinds of support I can } \\
\text { get from community programs and services to reach } \\
\text { my goals of life satisfaction. }\end{array}$ & 3.00 & 2.80 & -0.68 \\
\hline $\begin{array}{l}\text { Community programs and services provide support I } \\
\text { need to reach my goals of life satisfaction. }\end{array}$ & 3.00 & 2.70 & -1.68 \\
\hline
\end{tabular}

Finally, answering the previous calls of scholars focused on the implementation of the LAP (Messing et al., 2015), we gathered first hand perspectives of LAP participants' experiences with the LAP process. To begin, we asked participants who had received the LAP if they were told why the LAP was administered. And if so, what they were told about the LAP. Fifty-nine percent $(59 \%)$ of respondents who received the LAP reported being told why the LAP was administered. Respondents reported receiving a range of explanations that could be considered in 
This is an author-produced, peer-reviewed version of this article. The final, definitive version of this document can be found online at Violence Against Women, published by SAGE. Copyright restrictions may apply. https://doi.org/10.1177/1077801219880965. The content of this document may vary from the final published version.

alignment with the LAP protocol. For example, participants reported, "Because if you receive a certain score you can get extra services"; "It was a survey to see if I needed to talk to a counselor"; "Testing to see if you were high risk for safety and needed more information for report and protective order"; "To see if I was at high risk of danger". However, other participants reported explanations about the LAP that are not consistent with the aims and goals of the LAP. For example, one participant reported that she was told that the LAP was being completed because "it was something their supervisor wanted done" while others reported explanations that were unclear such as "something about a hotline" and "it has to be done because it was domestic violence". Many participants reported that they did not remember what they were told about why the LAP was administered, and a few of these participants cited that they were under distress at the time that they received the LAP and that this distress impacted their ability to remember what the law enforcement officer told them.

We then asked participants if they were informed of the results of their LAP screen. Thirty-eight percent (38\%) reported that they were told their results. Participants reported being told that, "she "screened in"; "had a positive result"; and "was eligible for high risk services". Other participants recalled being told that they "didn't fall into criteria"; "didn't qualify"; and "were not at high risk".

Regarding choice to participate, a high number of participants reported that they felt they had a choice to talk to the LAP administrator [law enforcement officer] and few participants regretted participating in the LAP. In addition, the majority of participants did speak to a hotline worker and indicated that speaking to the administrator of the LAP was helpful. Specifically, $81 \%$ of participants who received the LAP agreed or strongly agreed, "I had a choice regarding speaking to the administrator of the LAP about my relationship". While only $10 \%$ agreed or strongly agreed, "I regret speaking to the administrator [law enforcement officer] of the LAP about my relationship". Further, $73 \%$ of participants who were asked to speak to a hotline worker did and $68 \%$ agreed or strongly agreed that, "speaking to the administrator of the LAP about my relationship was helpful". Almost a quarter (24.4\%) of participants who spoke to the administrator about the results of the LAP reported that they took some type of action; participants reported [I] "got a protection order", "called a crisis worker", "called the hotline", "went to a shelter"; "changed house locks, had someone check computer and phone", and "filed charges".

Finally, when asked about taking actions after speaking with a hotline worker regarding the results of their LAP screen, $13.6 \%$ of participants reported that they took action; participants reported, [I] "got the interim [protective] order", "have a safebag ready", and "[became] more aware of surroundings, and [created] a safety plan".

\section{Discussion}

The present research examined a sample of domestic violence victims seeking legal services. Participants who reported receiving the LAP were compared with participants who reported that they had not received the LAP in regard to self-protective actions, service utilization, and empowerment. In addition, for victims who had received the LAP, the LAP process was explored. Findings demonstrated that LAP participants did not report greater rates of self-protective measures than non-LAP participants, which is contrary to the results from Messing et al. (2015). Given that the sample used here was comprised of women who were seeking legal domestic violence services, our findings likely reflect women using their own judgement regarding their safety regardless of their engagement in the LAP. Indeed, Campbell (1995) notes that women continuously assess their risk for re-assault within abusive relationships, and it may be that the women included in our sample are simply engaging in self-protective behaviors as they see fit - with or without the LAP. Further, unlike the Messing et al. (2015) study, the present study's treatment and comparison groups were not significantly different in regard to demographic characteristics or severity of domestic violence. As noted by Messing and colleagues, it is possible that the measured (as well as unmeasured) differences between their treatment and comparison groups influenced their finding that individuals in their treatment group engaged in greater rates of self-protective measures than individuals in their comparison group.

Consistent with prior research, we found that IPV victims who participated in the LAP did report greater rates of safety planning and more applications for previous protection/restraining orders than those who did not participate in the LAP. However, only a slight majority of individuals reported taking part in safety planning after receiving the LAP and few individuals cited applying for protective orders after the LAP. Given that part of the LAP protocol for victims who are assessed as high-danger is to access safety-planning strategies, it was expected that the LAP would lead to safety planning. The findings reported here do not provide strong evidence to that effect or that the LAP 
This is an author-produced, peer-reviewed version of this article. The final, definitive version of this document can be found online at Violence Against Women, published by SAGE. Copyright restrictions may apply. https://doi.org/10.1177/1077801219880965. The content of this document may vary from the final published version.

leads to other types of service utilization (i.e., shelter services, or counseling). Alternatively, results align with Johnson's (2010) contention that the complexity of women's decisionmaking and goals may not result in a linear progression from screening to services.

In addition, consistent with the goals of the LAP to provide (1) information to women about the risk of lethality and (2) a direct connection to services to assist in safety planning and counseling, it was expected that LAP participants would report higher empowerment. However, a comparison of empowerment items showed no significant differences between participants who reported that had received the LAP and those who reported that they had not received the LAP. Given that more than half of the current sample of domestic violence victims seeking services reported that they had not received the LAP, the question remains as to whether individuals who reported receiving the LAP would have still sought services with or without the LAP intervention.

At the same time, results do not empirically support concerns that the LAP process may have an explicit negative impact on women's empowerment. Most women reported feeling as though they had a choice in speaking with the hotline counselor, and few women regretted having done so. In addition, the majority of women did in fact choose to speak with someone at the scene, and most of those women agreed that the conversation was helpful. These findings support the aims of the LAP in regard to providing women with information that may assist them in making decisions about their future.

The findings from this study provide mixed support for the LAP's aim to raise awareness regarding victim danger. While a majority of respondents reported that they were told why they were receiving the LAP, explanations were not always consistent with the goals and aims of the LAP as described by the MNADV. In some cases victims reported that they were told that the LAP was associated with domestic violence or access to greater domestic violence services, but other victims reported being provided information that, while perhaps accurate (i.e., the officer's supervisor wanted the officer to complete the LAP), would have no impact on raising awareness of the dangers associated with domestic violence. Furthermore, several participants reported that they either did not know or could not remember what they were told about the LAP. This finding provides little evidence that the LAP process made a significant impact in communicating a sense of urgency around domestic violence to these victims.

Finally, we examined what victims were told about the results of their LAP screen. The findings from this research suggest that law enforcement officers must improve information sharing with victims during the LAP process. If the LAP is to be successful in raising victim's awareness about the dangers of domestic violence, law enforcement officers must communicate the outcome of the LAP to every victim. As described by Campbell (2004), "The process of risk assessment with a survivor of intimate partner violence gives the service provider access to the gold standard of information about the violence in the relationship but also makes the survivors a partner in that assessment so that they assess for themselves the extent of their danger (p. 1475). In other words, the LAP's strength is not in providing a tool for law enforcement to make decisions for women, but in providing a tool to increase the information women have when making decisions for themselves. As such, lack of communication and/or poor communication on the part of law enforcement regarding LAP screen results creates a missed opportunity to empower women with information to use in their on-going assessment of their own safety.

In addition, the results of the LAP screen must be described to victims with the limitations of the LAP in mind. The LAP screen only measures risk factors up to that point in time and does not measure many dynamic risk factors (i.e., partner's mood) that victims often use in their own self-assessments (see Connor-Smith, Henning, Moore, \& Holdford, 2011). Such limitations must be recognized; the LAP screen cannot be presented as a panacea for predicting a victim's future danger. Furthermore, officers must be clear with victims that a LAP screen that does not indicate high danger should never be used to mitigate a victim's own feelings that they are at a high risk for reassault or homicide (Kropp, 2004; Websdale \& Dedolph, 2000).

Although there was no direct evidence that women's empowerment is being decreased through the LAP process, there was also little evidence that empowerment was increased through the process. If women do not understand the purpose or meaning of the screen, their assessment outcome, or the limitations of the screen, the effectiveness of the LAP is arguably reduced. On the other hand, it is understood that programs utilized in the field must weigh victim safety, empowerment, and practical considerations (e.g., officer training, officer buy-in, the amount of time for the assessment, etc.). Fortunately, there is evidence that law enforcement is open to revising risk assessment to ensure complete victim understanding, consent, and empowerment. For example, Police Chief Goralski (2013) advocated for lethality assessment, while also encouraging consideration of Johnson's (2010) critiques and recommendations. 
This is an author-produced, peer-reviewed version of this article. The final, definitive version of this document can be found online at Violence Against Women, published by SAGE. Copyright restrictions may apply. https://doi.org/10.1177/1077801219880965. The content of this document may vary from the final published version.

Specifically, Gorlaski (2013) affirmed advocating for the use of lethality assessment while maintaining transparency about the nature of danger assessment and obtaining fully informed consent prior to engaging in assessment, concluding that "[...] if both transparency and informed consent are achieved, then the dignity of the DV victim undergoing a danger assessment can be properly protected by law enforcement officials conducting such assessments" (p. 244).

Current findings suggest that the LAP implementation protocol would benefit from additional prompts by law enforcement officers (or other LAP administrators) to confirm that victims understand the purpose of the LAP screen and the results of the LAP screen. As the LAP continues to evolve, increased victim empowerment and transparency as well as improved informed consent procedures could likely be achieved through the assistance of technology. Currently, the Danger Assessment is available for self-administration in the form of a free smart phone app, "myPlan" (Technology Safety, 2017). Specifically, myPlan asks users to fill out the 20-item Danger Assessment for their relationship, and indicates that " 10 or more 'yes' answers is concerning". It then directs users with 10 or more yes answers to call their local domestic violence shelter or the national domestic violence hotline. The app also provides options of resources for counseling, support and advocacy and safety planning information for users who indicate wanting to remain in or leave their relationship (Technology Safety, 2017). A similar app could be developed for the LAP: law enforcement officers open the LAP app on a smartphone screen, and then victims independently self-administer the Lethality Screen, receive their screen results, and accept or deny an on-screen offer to dial the hotline worker. While law enforcement officers are still available to answer questions, in this type of LAP administration, victims control each step in the decision-making process, and thus victim privacy and autonomy are increased.

Technology assisted LAP administration could also assuage potential concern regarding the consistency and accuracy of LAP implementation by officers on the scene. Implementation assessment remains an area of needed research in regards to lethality assessment. The results from this study demonstrate that victims' understanding and interpretation of the LAP process was variable. Findings also highlight the impact that the emotional nature of the situation may have on victims' ability to take-in and assess the information provided by law enforcement officers. While it has been posited that there may be an "optimal time for intervention shortly after an abusive episode" (Messing et al., 2014; p. 546; see also Curnow, 1997; McFarlane et al., 2004) there may be additional considerations to weigh. Connecting victims to services with immediacy (if desired) makes sense unless the stress of the situation impacts the ability of the victim to make an informed choice about talking with the hotline worker or participating in other types of services while in crisis. This concern echoes back to the complexity of women's decisionmaking (Johnson, 2010; Websdale \& Dedolph, 2000).

Given the disparate results between Messing et al. (2015) and the current study, additional replication research using treatment and control groups gathered at different points in the help-seeking process is needed to build a body of knowledge regarding the LAP's impact on self-protective measures. Future research would also benefit from capturing additional qualitative information from victims regarding their decisions to engage in self-protective measures or forego such actions as well as the temporal ordering of these decisions for victims who do and do not receive the LAP.

Future research should attempt to gather perspectives of women who were offered the LAP intervention and refused to further assess women's decisionmaking processes as well as their perspectives about their level of "choice" in regard to participation in the LAP. Women's reports about law enforcement reaction to their refusal to engage in the LAP and the impact of different types of law enforcement officer behavior post-refusal on victim's future helpseeking would be beneficial to improve law enforcement training on LAP implementation. Such information would also further inform the discussion regarding whether and/or how the LAP may impact victim empowerment.

The current research adds to the small but growing body of literature examining the association between the LAP, self-protective measures and service utilization, and provides new information about the LAP process. However, several limitations should be noted. First, significant differences were uncovered between individuals who agreed to participate in the study and those who declined to participate on several demographic variables including race, education, and whether the victim was currently living with a partner. As such the current findings may not hold for a sample with more non-White victims, victims with lower educational attainment, or victims who are currently living with their partner. In addition, the current sampling design focused on women who were currently seeking domestic violence legal services. While this design allowed for a treatment and comparison group in regard to the LAP, it inherently excluded victims who had not yet sought any domestic violence services. It is also logical to 
This is an author-produced, peer-reviewed version of this article. The final, definitive version of this document can be found online at Violence Against Women, published by SAGE. Copyright restrictions may apply. https://doi.org/10.1177/1077801219880965. The content of this document may vary from the final published version.

assume that the current sample may have higher levels of empowerment overall compared to victims of domestic violence who have yet to seek any services. Also, given the retrospective nature of the sampling design, it was not possible to verify participant's completion of the LAP or standardize the timeline regarding their LAP experience and completion of the survey. Finally, we focused on participants' experiences with domestic violence in the context of their current relationship only. It is possible that participants who have had prior abusive relationships may make different decisions and choices based on these previous experiences.

\section{Conclusion}

There is a strong and understandable desire to improve outcomes in domestic violence cases, and the point of first responder contact is a natural opportunity for intervention. The LAP's emphasis on connecting victims to services immediately following a call to law enforcement for domestic violence distinguishes the Lethality Screen from other actuarial risk assessments for domestic violence. The present analysis contributes to the developing body of research assessing law enforcement's adoption of domestic violence risk assessment in the field. As the LAP is implemented in different states across the U.S., continued evaluations are crucial to gauge the capability of the assessment tool to encourage self-protective measures and connect victims to domestic violence services while ensuring that victims' choices remain central to the process. 
This is an author-produced, peer-reviewed version of this article. The final, definitive version of this document can be found online at Violence Against Women, published by SAGE. Copyright restrictions may apply. https://doi.org/10.1177/1077801219880965. The content of this document may vary from the final published version.

\section{References}

Birdsall, N., Kirby, S., McManus, M. (2017). Police-victim engagement in building a victim empowerment approach to intimate partner violence cases. Police Practice and Research, 18(1), 75-86.

Canales, D., Macaulay, A., McDougall, A., Wei, R., \& Campbell, M. A. (2013). A brief synopsis of risk assessment screening tools for frontline professionals responding to intimate partner violence. Centre for Criminal Justice Studies: University of New Brunswick.

Campbell, J. C. (1986). Nursing assessment of risk of homicide for battered women. Advances in Nursing Science, $8(4), 36-51$.

Campbell, J. C. (1995). Assessing dangerousness. Newbury Park, CA: Sage.

Campbell, J. (2004). Helping women understand their risk in situations of intimate partner violence. Journal of Interpersonal Violence, 19(12), 1464-1477.

Campbell, J. C. (2005). Commentary on Websdale: Lethality assessment approaches: Reflections on their use and ways forward. Violence Against Women, 11(9), 1206-1213.

Cattaneo, L. B. \& Goodman, L. A. (2010). Through the lens of therapeutic jurisprudence: The relationship between empowerment in the court system and well-being for intimate partner violence victims. Journal of Interpersonal Violence, 25(3), 481-502.

Connor-Smith, J. K., Henning, K., Moore, S., \& Holdford, R. (2011). Risk assessments by female victims of intimate partner violence: Predictors of risk perceptions and comparison to actuarial measure. Journal of Interpersonal Violence, 26(12), 2517-2550.

Curnow, S. A. (1997). The open window phase: Helpseeking and reality behaviors by battered women. Applied Nursing Research, 10(3), 128-135.

Dutton, D. G. \& Kropp, P. R. (2000). A review of domestic violence risk instruments. Trauma, Violence, \& Abuse, l(2), 171-181.

Goodman, L. A., Dutton, M. A., \& Bennett, L. (2000). Predicting repeat abuse among arrested batterers: Use of the Danger Assessment scale in the criminal justice system. Journal of Interpersonal Violence, 15(1), 63-74.

Goralski, C. S. (2013). Domestic violence: Firearm seizures \& lethality assessments: Enhancing the police response. The Police Journal: Theory, Practice, and Principles, 86(3), 235-248.

Hanson, R. K. (2005). Twenty years of progress in violence risk assessment. Journal of Interpersonal Violence, 20(2), 212-217.

Hanson, R. K., Helmus, L., \& Bourgon, G. (2007). The validity of risk assessments for intimate partner violence: A meta-analysis. (Corrections Research User Rep. No. 2007-07). Ottawa, ON: Public Safety Canada. Retrieved from http://cbrnonline.psepc.gc.ca/cnt/rsrcs/pblctns/ntmt-prtnr-vlnce/ntmt-prtnr-vlnce-eng.pdf

Hoyle, C. (2008). Will she be safe? A critical analysis of risk assessment in domestic violence cases. Children and Youth Services Review, 30, 323-337.

Johnson, M. E. (2010). Balancing liberty, dignity, and safety: The impact of domestic violence lethality screening. Cardozo Law Review, 32(2), 519-580.

Johnson, D.M., Worell, J., \& Chandler, R. (1998). The Personal Progress Scale-Revised (PPS-R). Unpublished manuscript.

Johnson, D. M., Worell, J., \& Chandler, R.K. (2005). Assessing psychological health and empowerment in women: The Personal Progress Scale Revised. Women \& Health, 41(1), 109-129.

Klein, A. R. (2012). Lethality assessments and the law enforcement response to domestic violence. Journal of Police Crisis Negotiations, 12(2), 87-102.

Kropp, P. R. (2004). Some questions regarding spousal assault risk assessment. Violence Against Women, 10(6), 676-697.

Maryland Network Against Domestic Violence (MNADV) (2009, Spring). MNADV Newsletter: Reading the signs. Retrieved from http://www.mnadv.org/Spring\%20LA\%20Newsletter09.pdf.

Maryland Network Against Domestic Violence (MNADV). (2011). Lethality assessment program Maryland Model for first responders: Learning to read the danger signs. Retrieved from http://mnadv.org/_mnadvWeb/wpcontent/uploads/2011/10/LAP_Info_Packet--as_of_12-8-10.pdf

Maryland Network Against Domestic Violence (MNADV). (n.d.) How LAP works. Retrieved from https://lethalityassessmentprogram.org/about-lap/how-lap-works/

Maryland Network Against Domestic Violence (MNADV). (2016). "Lethality Assessment Program. Maryland Model. LAP.-Maryland Annual Report Summary 2015.” MNADV, Lanham, MD. Retrieved from http://mnadv.org/_mnadvWeb/wp-content/uploads/2016/03/2015-LAP-Maryland-Annual-ReportSummary.pdf 
This is an author-produced, peer-reviewed version of this article. The final, definitive version of this document can be found online at Violence Against Women, published by SAGE. Copyright restrictions may apply. https://doi.org/10.1177/1077801219880965. The content of this document may vary from the final published version.

McFarlane, J., Malecha, A., Gist, J., Watson, K., Batten, E., Hall, I., \& Smith, S. (2004). Increasing the safetypromoting behaviors of abused women. The American Journal of Nursing, 104(3), 40-51.

Messing, J. T. \& Campbell, J. (2016). Informing collaborative interventions: Intimate partner violence risk assessment for front line police officers. Policing: A Journal of Policy \& Practice, 10(4), 328-340.

Messing, J. T., Campbell, J. C., Brown, S., Patchell, B., Androff, D. K., \& Wilson, J. S. (2014). The association between protective actions and homicide risk: Findings from the Oklahoma Lethality Assessment Study. Violence \& Victims, 29(4), 543-563.

Messing, J. T., Campbell, J. C., Ward-Lasher, A., Brown, S., Patchell, B., \& Wilson, J. S. (2016). The lethality assessment program: Which survivors of intimate partner violence are most likely to participate? Policing: An International Journal of Police Strategies \& Mangement, 39(1), 64-77.

Messing, J. T., Campbell, J. C., Webster, D. W., Brown, S., Patchell, B., Wilson, J. S. (2015). The Oklahoma Lethality Assessment Study: A quasi-experimental evaluation of the lethality assessment program. Social Service Review, 89(3), 499-530.

Messing, J. T., Campbell, J., Wilson, J. S., Brown, S., \& Patchell, B. (2017). The Lethality Screen: The predictive validity of an intimate partner violence risk assessment for use by first responders. Journal of Interpersonal Violence, 32(2), 205-226.

Messing, J. T., Campbell, J., Wilson, J. S., Brown, S., Patchell, B., \& Shall, C. (2014, July). Police Departments' Use of the Lethality Assessment Program: A Quasi-Experimental Evaluation. Final Report, NCJ-247456. Washington, D.C.: U.S. Department of Justice.

Messing, J. T., Cimino, A., Campbell, J. C., Brown, S., Patchell, B., \& Wilson, J. S. (2011). Collaborating with police departments: Recruitment in the Oklahoma Lethality Assessment (OK-LA) study. Violence Against Women, 17(2), 163-176.

Messing, J. T. \& Thaller, J. (2013). The average predictive validity of intimate partner violence risk assessment instruments. Journal of Interpersonal Violence, 28(7), 1537-1558.

Nicholls, T. L., Pritchard, M. M., Reeves, K. A., \& Hilterman, E. (2013). Risk assessment in intimate partner violence: A systematic review of contemporary approaches. Partner Abuse, 4(1), 76-168.

Piquero, A. R., Brame, R., Fagan, J., \& Moffitt, T.E. (2006). Assessing the offending activity of criminal domestic violence suspects: Offense specialization, escalation, and de-escalation evidence from the Spouse Assault Replication Program. Public Health Reports, 121(4), 409-418.

Robinson, A. L. \& Rowlands, J. (2009). Assessing and managing risk among different victims of domestic abuse: Limits of a generic model of risk assessment? Security Journal, 22, 190-204.

Storey, J. E. \& Hart, S. D. (2014). An examination of the danger assessment as a victim-based risk assessment instrument for lethal intimate partner violence. Journal of Threat Assessment and Management, 1(1), 5666.

Straus, M. A., Hamby, S. L., Boney-McCoy, S., \& Sugarman, D. B. (1996). The Revised Conflict Tactics Scales (CTS2): Development and preliminary psychometric data. Journal of Family Issues, 17(3), 283-316.

Websdale, N. \& Dedolph, B. (2000). Lethality assessment tools: A critical analysis. Retrieved from https://vawnet.org/material/lethality-assessment-tools-critical-analysis 